\title{
Systematizing Environmental Indicators and Indices
}

\author{
Robert P. Blauvelt \\ GEI Consultants, 1 Greenwood Avenue, Suite 210, Montclair, New Jersey 07042 \\ United States of America
}

Tel: 1-973-873-7127Ｅ-mail: rblauvelt@geiconsultants.com

\begin{abstract}
Received: December 31, 2013 Accepted: February 19, 2014 Published: March 26, 2014
doi:10.5296/jee.v5i1.4864 URL: http://dx.doi.org/10.5296/jee.v5i1.4864
\end{abstract}

\begin{abstract}
Environmental indicators and indices are detailed and complex devices that attempt to describe not only ecological status but also the reactions of the biosphere to the demands placed on it by society. Researchers have proposed the use of hundreds of different environmental indicators to evaluate everything from socially responsible investing, to the effects of governmental policies, and even cultural survivability. However, an unqualified environmental or sustainability index cannot be developed given the innate complexity of natural systems in combination with the influence of human activities on those systems. The trend in indicator development is toward the compilation of environmental and sustainability data sets and indices that are more encompassing. Therefore, it becomes essential to identify the fundamental system attributes indicators are measuring and indices are aggregating.

This paper provides an overview on the make-up and limitations of environmental and sustainability indicator sets based on the driver, pressure, state, impact, response (DPSIR) framework. It goes on to suggest a technique to categorize environmental and sustainability indicators based on their alignment with DPSIR. Environmental or sustainability indicators and their associated indexes can be arranged into categories that are distinct, well defined and transferrable, regardless of the degree or intensity of aggregation. By so doing, the underlying preferences inherent in the index or data set are revealed and the user/decision maker/policy advocate is able to evaluate the full context of the information being presented.
\end{abstract}

Keywords: Environmental indicators, Sustainability index, Aggregation, DPSIR, Systematizing, Categories 


\section{Introduction}

Environmental indicators have been in use since ancient times when nomadic tribes would rely on the length of day, temperature, and wind direction to anticipate the change of seasons, the movement of game, or when to plant crops (Malville, 2012). As our ability to measure environmental conditions improved, so did the desire to aggregate those data into useful predictive or management tools: "Listen for the sound of the first cicadas. The first frost of the year will occur about three months later" (Old Farmer's Almanac, 2011). Environmental indicators and indices have matured into detailed, complex devices that attempt to describe not only ecological status, but also the reactions of the biosphere to the demands placed on it by society.

A recent survey of the literature identified over 40 environmental and sustainability indices many of which are mathematically complex and multidimensional; incorporating socioeconomic as well as ecological parameters (Singh et al., 2012). In one of the first systematic evaluations of environmental indicators Ott (1978) described environmental indicators/indices as a way to reduce a large amount of information to a useful form, yet still credibly answer the questions being asked. An unqualified environmental index cannot be developed given the innate complexity of natural systems in combination with the influence of human activities on those systems. However, an imperfect set of environmental indicators or indices is a better tool than none at all (den Butter et al., 1998).

As environmental and sustainability indicator data sets and indices grow more encompassing, it becomes essential to identify the fundamental system attributes that indicators are measuring and indices are aggregating (Mayer, 2008). This paper suggests a technique to categorize environmental and sustainability indicators based on their alignment with the Driver-Pressure-Impact-State-Response (DPSIR) paradigm. By so doing, the underlying preferences inherent in an index or data set are revealed and the user/decision maker/policy advocate is able to evaluate the full context of the information being presented.

\section{What Makes an Effective Environmental Indicator?}

An indicator, whether ecological, economic, or political, provides reliable, readily comprehensible information on the status of complex, dynamic systems (Niemeijer and de Grott, 2008). Environmental indicators serve to do this for specific types of human interactions with physiochemical processes such as the effects of industrial wastes on air or water. Environmental indicators have evolved from simple measures of output (pounds of pollutant) to those attempting to interconnect degrees of economic development and societal wellbeing with consumable rates (sustainable or not) of natural resource exploitation (Lee, 2001).

Researchers have proposed the use of hundreds of environmental indicators to evaluate everything from socially responsible investing, to the effects of governmental policies, and even cultural survivability. Despite the disparate purposes and objectives of environmental indicators, a review of the basis for their selection and use does bring to light a set of generally consistent themes. The commonality of these themes is dependent upon 
environmental indicators that are consistently quantifiable, significant, communicative, and multidimensional.

To be meaningful, environmental indicators must be measureable (Smeets and Weterings, 1999). They need to dependably gauge and compare the activity of a system at a given place and time against a set of pre-selected standards or benchmarks (e.g., carbon dioxide levels or species diversity). The scale and duration of measurements will vary with the process or processes being monitored; but the indicator's ability to highlight the difference between current status and a desired target or goal is critical to its practicality and efficacy. Knudsen et al. (2010) used a variety of measures to assess fishery status along the coast of the Black Sea near Turkey. Major factors they identified as contributing to declining eco-system productivity included, among other things, expanded use of electronics (echo sounders, GPS), smaller net mesh size, uneven enforcement of fishing regulations, and more powerful boats. Knudsen connected these specific, well-documented metrics to policy recommendations aimed at stemming overfishing and improving habitat sustainability.

Environmental indicators should reveal more about a system than their measurements record (Niemeijer, 2002). The most important indicators or sets of indicators - sometimes called leading indicators because they imply a predictive ability - are those whose significance extends beyond that event or process being observed and catalogued. They provide clues, signals, or even warnings about trends or phenomenon that would not be otherwise obvious. For example, changes in ocean water acidity $(\mathrm{pH})$ have long term atmospheric and ecological implications that go beyond a simple measurement of the number of hydroxyl ions present in a sample of salt water (Feely et al., 2004). Global changes in ocean water pH may influence ecosystem function at the very base of the food web and this metric could be considered a leading indicator in policy discussions of climate change impacts and mitigation.

The main purpose of most environmental indicators is to facilitate communication between scientists, policy makers, issue-connected stakeholders, and the public (Giannetti et al., 2009). An effective environmental indicator will be able to distill the workings of a complex system or set of relationships into an accessible, meaningful précis without the loss of scientific credibility. An example is the U.S. Environmental Protection Agency's Air Quality Index or AQI (USEPA, 2009). The AQI aggregates hundreds of hourly measurements for four pollutants and ranks the air in a particular region as Good (AQI Scores of less than 50) through Hazardous (AQI Scores of greater than 500). Each of the six AQI levels also is assigned a color code so that a quick visual assessment can be made by an interested party, say a television broadcaster. The AQI meets all of the communication criteria for an effective environmental indicator: it is scientifically sound, meaningful, and simple to understand.

Note that the AQI, like many environmental indicators and indexes, is multidimensional; it captures data on an ongoing basis not only on pollutant loading, but also weather conditions and other factors. It then assesses this information to make predictions regarding potential health impacts to sensitive populations at a specific time and place. Multidimensionality, however, means that a single or even a series of measurements will be unable to represent the 
full effect of human activity on a complex and interrelated environment (Hoag et al., 2002). Our still evolving understanding of global processes and local ecologies drive the conclusion that indicators, by their very nature, are incomplete.

As part of the effort to develop a universal set of indicators, there are ongoing discussions on how to select, prioritize, and combine those environmental standards that are most important to a country, population, or economy. To rein in or at least bracket the need to consider all aspects of an industrial or commercial activity's impact on a system, many environmental indicators are focused on specific objectives or value schemes. They seek to represent the performance of a set of limited environmental or ecological components associated with a broader, more complex operating system. Tourism can have significant impacts on local ecologies (Collins et al., 2012). Choosing indicators reflective of those impacts can play a major role in setting local response priorities. Hughes (2002) analyzes a series of indicators to assess potential impacts from diving, sight-seeing, and other activities on a coral reef. He proposes a balancing concept that allows for economic and social development while minimizing environmental degradation.

Combining the above characteristics yields a representation of an ideal environmental or set of ideal environmental indicators. On a technical basis the indicator(s) must be able to reliably measure accessible and meaningful system-based data, draw attention to changes in ecosystem status, and offer extrapolative insight into likely future consequences of ongoing or anticipated social policies. Within a societal context, an essential requirement of the indicator(s) is to be able to effective communicate and be reflective of stakeholder's priorities and principles.

\section{The Value and Role of Environmental Indictors}

Environmental indicators describe trends or patterns in ecosystem functions as altered by anthropogenic inputs. They also serve to measure and document the effectiveness of policy responses implemented to address environmental challenges or concerns (Siracusa et al., 2004). Environmental indicators are predictive, offering a vision of water, air, or habitat quality in light of past or ongoing pollutant or ecosystem stressors. Finally, environmental indicators can help align societal and business values, focusing resources on those issues considered most important by stakeholders.

The collection and analysis of environmental data and their compilation or assembly into indicators has, as one of its goals, the identification of spatial and temporal differences in public health and ecosystem reactions to pollution (Cendrero, 2003). Once synthesized and evaluated, environmental indicators attempt to connect contaminant levels or changes in pollutant loadings with permutations in environmental or life quality. Environmental and public health trend/impact analyses of atmospheric lead, chlorofluorocarbons, and carbon dioxide helped convince global policy makers to institute and enforce near-term regulatory and incentive programs to reduce the concentrations of these compounds in air.

Measuring the effectiveness of public policy choices and validating the success of environmental improvements also is a relevant function of environmental indicators. Data 
recording the effects of implementing a particular approach to an environmental concern offers an opportunity to evaluate past strategies and, if necessary, re-direct future efforts (Radu, 2012). One such policy change currently being tested with the help of air quality indicators is the movement away from a strictly regulatory control system for acid rain pre-cursors (primarily sulfur dioxide) to a market based approach. Cap-and-trade programs provide economic incentives to limit (cap) discharges by allowing companies to sell (trade) excess pollution credits to industries that cannot meet their air discharge ceilings (Burtraw et al. 2005). There is a nationwide market in United States for sulfur dioxide credits and small, more localized trading centers for nitrogen oxides, a smog-producing chemical. Similar cap and trade initiatives have been undertaken in Europe for carbon dioxide (Neuhoff et al., 2006). The effectiveness of this change in regulatory policy on environmental quality and economic performance is still being evaluated, but significant reductions in pollutant discharges have been documented (Schakenbach et al., 2006).

While many environmental indicators are lagging or static - used to consider the effects of past activities on current environmental quality - some are prospective or leading, alerting policy makers to patterns and tendencies as well as trying to stave off environmental injury and its related adverse social and economic consequences. Examples of prospective or predictive environmental indicators include such eco-system stressors as urbanization, agricultural chemical usage, and energy consumption, as well as the socio-political metrics of population growth, international commitments to pollution-reduction treaties, and governmental spending on environmental improvements. These indicators aid in defining critical environmental issues for stakeholders as well as in measuring progress toward achieving improvement goals. In New Jersey, commercial and residential development has led to increasing amounts of nitrogen and phosphorous entering Barnegat Bay, a 30 mile long, five mile wide Atlantic Ocean coastal estuary (Kennish et al., 2007). With eutrophication looming for this important commercial and recreational resource, New Jersey legislators established the most restrictive standards in the nation for nitrogen content in fertilizer as well as strictly limiting application rates (Spahr, 2011). If enforced properly, these standards will reduce nutrient pollution in all of New Jersey's water bodies, including Barnegat Bay.

Changes in climate, habitat, or water quality indicators can signal what environmental and societal quality will be years or decades from now and allows resources to be focused to address critical concerns (Esty and Samuel-Johnson, 2001). Pesticide use, an oft cited environmental indicator, and its impact on American bald eagle eggs, led to a ban on DDT and many other organo-chlorinated agricultural chemicals. Nearly extinct by the late 20th century, thanks to more restrictive pesticide usage and habitat stabilization and protection programs, bald eagles are no longer considered endangered and populations have stabilized (Roeder Martin, 2008).

One developing use of indicators is to better align business practices with global and local environmental concerns (Kolk and Mauser, 2002). Private companies rely on clearly defined environmental indicators as diagnostic instruments; a data derived set of performance measures that allows comparisons with competitors, opportunities for image or reputation enhancement, and the measureable integration of environmental values into management 
structures. Environmental indicators also are used by financial professionals in assessments of a company's commitment to corporate social responsibility, a more and more conspicuous institutional investment guideline (Thomas et al., 2007).

One example of the role of environmental indicators in business settings is seen in the Canadian Boreal Forest Agreement. After evaluating the impacts of its logging practices on eco-system sustainability, and spurred on by consumer pressure and data provided by environmental and habitat protection stakeholders, Forest Products Association of Canada joined with nine leading environmental groups to develop and implement resource practices in the boreal forest (Boychuk, 2011). These new logging and restoration methods will preserve biosphere for woodland caribou and protect long-term access to sustainable levels of raw materials. Under the 2010 agreement, new logging will be suspended on nearly 29 million hectares (112,000 square miles) of boreal forest and, in return, the environmental groups stopped their "Do Not Buy" campaigns (Greenpeace, 2010).

Subsequent to their selection and validation, environmental indicators (EIs) play a key role in developing and justifying the implementation of environmental policies. They also form the basis for measuring the effectiveness (success or failure) of those strategies. EIs are becoming more and more important in benchmarking corporate environmental performance that allows socially responsible, for-profit organizations to enhance their image or improve a competitive position.

\section{DPSIR}

A widely adopted device that systematizes the collection and assembly of environmental data into meaningful indicators is the Drivers, Pressures, State, Impact, Response or DPSIR schema. Developed in the late 1990s by the European Environment Agency (Hong and Lee, 2006; Spangenberg et al. 2009), the DPSIR framework is a series of indicators that seek to integrate human activities, pollutants, and ecosystem conditions with human health and environmental effects and the associated societal reaction. Figure 1 illustrates the relationships among DPSIR indicators.

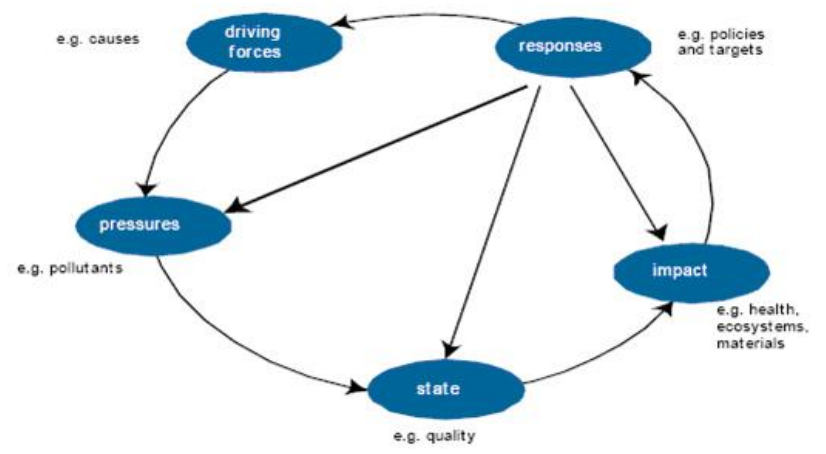

Figure 1. DPSIR indicators and how they interrelate. Note Responses will influence the other stages of the framework (European Commission, 2012)

Drivers are those things people need or require for healthy and fulfilled lives. At the most 
basic level these include clean water, a reliable food supply, shelter, economic security, and social stability (Kristensen, 2004). The pursuit to satisfy or resolve these needs (Drivers) results in increased resource utilization which, if realized through uncontrolled or ill-thought out interactions with the ecosystem, can lead to environmental degradation. Drivers are exogenous and can be direct or indirect; with direct Drivers classified as those that have the most readily observable, near-term measureable influence on environmental quality. Changes in the demographics or economic structure of a nation or group are examples of direct Drivers; forcing transformation of the ecosystem quickly, from the inside outward. Indirect Drivers are those that influence environmental quality more subtly and over a longer time. Shifts in cultural practices or religious beliefs are those indirect Drivers that can begin to alter the ecosystem along its edges or margins, and instigate change from the outside inward.

The dynamics that motivate human behavior to meet a need, either through productive or consumptive processes, exert Pressure on the environment. These endogenous forces are generated by specific human needs and, when acting on the ecosystem, are manifested in changes to environmental conditions, for example, the appearance of higher carbon dioxide concentrations in air (Gabrielsen and Bosch, 2003). Environmental Pressures also come into play through natural causes that have undesirable ecosystem consequences such as volcanic eruptions, tsunamis, or asteroid collisions. The goal of sustainable development programs is to accommodate ever increasing Drivers (economic activity) while holding steady or even decreasing the resulting Pressures on the environment (pollution levels).

State is the condition of the environment at a specified time and place. It can be represented by such indicators as surface water oxygen content or ambient levels of ground level ozone. State is not static and includes information on pollutant dispersion patterns and temporal trends and represents the totality of the ecosystem: physical, chemical, and biological (Mourao et al., 2004). State indirectly measures the carrying capacity of the ecosystem, its ability to adjust to Pressures. State also defines the relationship between Drivers and Pressures, illustrating what changes in one does to the other.

Impacts are the consequences of Drivers and Pressures and are quantified or described by State. Impact indicators are descriptive and introduce into the DPSIR framework the direct effects of environmental Pressures on human health and ecosystem function as well as economic and social performance. Impacts can be interrelated or occur in sequence with increased air pollution affecting temperature which diminishes agricultural outputs that result in famine (Sekovski et al., 2012). As Impacts are defined by only those changes that influence the use of ecosystems by people, it would only be this last step (famine) that would qualify as an Impact within the DPSIR system. Changes in temperature and agricultural output are States, measuring the extent of environmental change.

To manage or control Impacts, and ultimately to reduce Pressures, the affected community initiates or applies a Response. These Responses are, or should be, prioritized by Impacts and 
can include formal policies (regulation) and informal coping mechanisms (customer purchase preferences). The degree or scope of societal Response depends on Impact credibility, which relies heavily on how Impacts are measured and presented (State) and ultimately perceived by policy makers and other stakeholders (Tscherning et al., 2012). Responses also can be considered as negative Drivers as they are intended to preserve desirable ecosystem functions while lessening Impacts.

\section{Limitations to DPSIR}

DPSIR is not an analytical model, but rather a methodology to organize and present indicators in a manner useful for researchers, policy makers, and stakeholders (Carr et al., 2007). However, depending upon the objectives of the indicator data sets and indices being aggregated and evaluated, the DPSIR framework has its limitations. These include its relativism, reactive (non-proactive) nature, linearity, and inherent hierarchical structure.

DPSIR does not incorporate reference values or baseline levels; it is relativistic in nature, comparing environmental or sustainability status measurements with either temporal or spatial equivalents (Aguilera-Caracuel et al., 2012). Without an acknowledged or set starting point the identification of trends and the effects of policy changes (Responses) implemented to address environmental concerns (State or Impacts) are difficult to quantify and assess (Bauler, 2012). To illustrate this point, the Environmental Sustainability Index or ESI (Emerson et al., 2012) is a widely cited indicator set organized within the DPSIR framework. Wilson et al. (2007) compares the ESI to five other sustainable development indices and describes a lack of consistency in the selection and aggregation of indicator metrics. This leads to a high degree of variability in global sustainability rankings with, for example, Canada ranked No. 4 in sustainable development by one index and No. 15 (out of 15 countries) in another. This lack of metric correspondence offers policy makers little clear guidance (or confidence) as to which measures of sustainability are accurate and reliable.

Measurements and interpretations of State or Impact within DPSIR based indices and indicator sets infer that the damage or undesired effect has already occurred (Babcicky, 2012). DPSIR indicators need to be collected, analyzed, and evaluated over time (yearly, biennially, etc.). This recurring examination of environmental conditions changes those indicator sets and indices structured around DPSIR to reactive tools; unable to predict or readily address new or developing threats and concerns (Spangenberg et al., 2002). These temporal handcuffs permit data assessments to occur only within the metes and bounds of narrowly defined State or Impact measurements, limiting proactive Response options that might have been more available if dynamic (real-time), quantifiable (less relativistic) feedback mechanisms had been in place.

DPSIR represents a continuum on a cause and effect environmentally defined procession (Niemeijer and de Groot, 2008). Distinguishing an Impact (famine) from a State (inches of rain per year) can be problematic as indicators can be re-defined or recast as States (food intake per person) or even as Drivers (population migration). In a 2006 summary of Canadian and US environmental indicators, the United Nations Environmental Programme (UNEP, 2006) divided environmental and sustainability indicators from four organizations: 
National Round Table on the Environment and Economy (Canada); Environment Canada, United States EPA, and The Heinz Center (USA) into DPSIR categories. In five categories (agricultural land, toxic substances, waste, freshwater resources, and grasslands or shrub lands) indicators defined as States by one organization were classified as Pressures or Responses by another.

The DPSIR paradigm implies distinct, linear (downhill) links or causalities between indicators (Binimelis et al., 2009). Such a view contrasts sharply with the realities of the complex, interconnected networks operating within environmental and societal systems. Despite enhancements by several researchers (Carr et al., 2007; Tscherning, et al., 2012) DPSIR based indices and indicator sets tend either to marginalize or not address these interconnections. In an analysis prepared by Niemijer and de Groot (2008) the DPSIR causal chain framework is used to illustrate how, in the case of greenhouse gas (GHG) emissions, increasing fossil fuel usage (Pressure) resulted in changes to carbon dioxide levels (State) that in turn instigated energy efficiency programs (Response). However, Niemijer and de Groot go on to point out that this simple causal chain does not take into account other Pressures, States, and Responses that also influence atmospheric GHG levels. Changes in land use (urbanization), agricultural and grazing intensity, industrialization, and population growth serve as indicators for other environmental and sustainability outcomes, but also need to be considered as measures associated with predicting DPSIR effects for GHGs.

Fundamental to DPSIR based indicators and indices are an imputed hierarchy (Tscherning et al., 2012). This hierarchical structure expresses itself through an emphasis and focus on large scale, far-reaching metrics. There is no obvious pathway for global or even regionally measured Impacts and States to be converted into local Responses (Carr et al., 2007). In addition, DPSIR framework indicators and indices tend to marginalize input from local stakeholders. Communities in developing or under-developed areas often are left to deal with the consequences of governmentally conceived Responses that they had little influence in developing and will have no control over in implementation (Bell, 2012). In an example cited by Carr et al. (2007), park managers in India introduced fast-growing, non-native species in order to show progress towards international goals developed in reliance on a DPSIR-based sustainability framework on improving canopy acreage (Robbins, 2001). However, the plants introduced adversely impacted native biodiversity and were inconsistent with local economic needs.

The limitations of the DPSIR framework revolve around a series of tenets which, depending upon the context of their application and the skills of the practitioner, may limit its effectiveness and utility. DPSIR's lack of an absolute scale can lead to confusion in ranking or evaluating ecosystem status measurements while a reactive (backward looking) emphasis can disguise or inhibit reliance on its predictive capability. Incorporating DPSIR based indicators into local value systems has not been widely adopted and the use of DPSIR as a simple cause and effect model is not consistent with the multifaceted socioeconomic forces functioning within the area or region being evaluated.

\section{Improvements to DPSIR}


Despite its limitations, DPSIR is a dominant framework for the organization and evaluation of environmental/sustainability indicators and indices and likely will remain so into the foreseeable future (Karageorgis et al., 2006; Kohsaka, 2010). To improve its usability and acceptance, enhancements to DPSIR based methodologies should be focused around indicator standardization and quantification to allow for more comparability between regions and countries; establishing a common basis for stakeholder input and participation in indicator selection and weighting; more effective integration among DPSIR factors to account for apparent and abstruse ecological and anthropogenic system interdependencies; and procedures to evaluate the effectiveness of change (environmental improvement) to response (policy initiatives).

Singh et al. (2012) evaluated over 40 sustainability indices describing each by the number of indicators and sub-indicators, including how the indicators are scaled, weighted, and aggregated. Each of these indices has their own objectives and to try and join or normalize them would require extensive exegetical and re-interpretative efforts. In an attempt to bring a more universal approach to indicator selection and analysis, Organisation of Economic Co-Operation and Development (OECD) and the European Commission has developed guidelines for the formulation of composite indicators (OECD, 2008). The techniques described by the OECD handbook include indicator selection and data reduction and are directed towards comparing and ranking country performance in areas such as industrial competitiveness and sustainable development. One technique to analytically amalgamate indictors and indices that continues to develop is described by Potschin (2009). SENSOR (www.sensor-ip.eu) is a model that identifies common, inter-country land use indicators (environmental, social, and economic) and allows the consequences of different policy options (responses) to be assessed through 2025. In this way, the implications of land use change, regionally and at larger scales, can be evaluated within the context of near and long term environmental or sustainable objectives.

"Top down" indicator selection is done by researchers and scientists seeking to choose those performance measures most reflective of the DPSIR framework they are seeking to capture, often at regional or global scales. "Bottom up" indicator selection stresses local stakeholder input and weighting on DPSIR factors that operate or affect communities and economic environments (Mayer 2008). As in politics, all environment is local and for sustainability and ecosystem indicators and indices to be credible and reliable, they must contain "top down" as well as "bottom up" inputs.

Bell (2012) and Tscherning et al. (2012) describe techniques to identify and quantify local stakeholder input during the indicator evaluation and weighting process. They acknowledge that many prior DPSIR based environmental and sustainability indices generally have made only modest efforts to incorporate indigenous knowledge and values. The authors go on to conclude that a more inclusive and transparent indicator selection program is essential to the continued relevance of the DPSIR framework.

The development and implementation of a DPSIR framework for ecosystem or sustainability assessment is an ongoing one where indicators, states, impacts, and other metrics are selected, 
measured, and continuously refined (Bertollo, 1998). They are not immutable, but meant to evolve and change so as to blend eco-economic conditions at a given place and time. As DPSIR systems mature (temporally and spatially) linkages will become apparent between Pressure and State, State and Response, and Response and Pressure (Neimeijer, 2002). Defining and quantifying these linkages would reveal those socioeconomic and environmental relationships that are significant actors in DPSIR based models.

To better clarify and quantify DPSIR linkages, Niemeijer and de Groot (2008) introduced the concept of an enhanced or eDPSIR. This approach views DPSIR processes as causal networks rather than causal chains and seeks to identify key DPSIR factors within the context of dose-response ecosystem functions. Expanding the dimensionality of DPSIR, Maxim and Spangenburg (2009) introduce the tetrahedral DPSIR, focused on the identification and analysis of chemical drivers or pressures on the environment, particularly biodiversity. The DPSIR framework is conceptually inflated by classifying and evaluating primary (chemical discharges), secondary (materials governance), and tertiary (cultural attitude) aspects. This third dimension to DPSIR is expressed more quantitatively by Lin et al. (2009) through matrix analysis of their Ecological Hierarchy Network or EHN. In this approach, DPSIR factors (e.g., indicators) are mathematically arranged or layered around an ecosystem's environmental status. The EHN then integrates the layers to identify and interpret the most meaningful hierarchical relationships. This tends to minimize or reduce the level of subjectivity inherent within some DPSIR based analysis.

As analytical tools become more available for quantifying DPSIR framework systems, techniques are developing to judge the effectiveness of a policy initiative (Response) with regard to a change in environmental status (State). Is the Response achieving the desired change in State? Confounding the process are such issues as data (i.e., indicator) gaps, measurement quality, and data sensitivity (Niemeijer, 2002). More difficult to address is the response time or "distance to target" between policy initiative and environmental response (Conacher, 1998). Ecosystem response time increases in proportion to scale as seen in the case of chlorofluorocarbons (CFCs) and ozone layer depletion (Table 1):

Table 1. Summary of Ozone Layer Depletion History (www.epa.gov/ozone)

\begin{tabular}{|c|c|l|}
\hline Date & $\begin{array}{c}\text { Elapsed } \\
\text { Time } \\
\text { (years) }\end{array}$ & \multicolumn{1}{|c|}{ Activity } \\
\hline $\begin{array}{c}\text { Late } \\
\text { 1920s }\end{array}$ & --- & CFCs introduced for commercial use as a refrigerant. \\
\hline $\begin{array}{c}\text { Early } \\
\text { 1970s }\end{array}$ & 50 & $\begin{array}{l}\text { Studies begin to evaluate the impacts of CFCs on atmospheric } \\
\text { chemistry, including ozone formation. }\end{array}$ \\
\hline Mid 1980s & 15 & $\begin{array}{l}\text { Widespread consensus is reached in the scientific community } \\
\text { that the ozone layer above the Antarctic has thinned. Later } \\
\text { research confirms decreasing ozone levels in other parts of the } \\
\text { world. }\end{array}$ \\
\hline 1996 & 10 & Most industrialized countries ban the use of CFCs. \\
\hline $1997-1998$ & 2 & Chlorine levels in the atmosphere peak and begin to decline. \\
\hline 2060 & 62 & $\begin{array}{l}\text { The date when atmospheric chlorine concentrations are expected } \\
\text { to return to pre-CFC use levels. }\end{array}$ \\
\hline
\end{tabular}


CFCs played a major role in the economies of most developed countries and significant geopolitical inertia had to be overcome to initiate measures to regulate and/or phase out their use. 25 years of monitoring and confirmatory studies were necessary before policy makers acted decisively and another 60 years is required before the desired ecosystem endpoint (atmospheric chlorine at pre-CFC use levels) will be achieved. A similar process, albeit with a much extended time-line, is being played out today with regards to greenhouse gas emissions and their effects on global climate.

On a more regional scale, Maybeck et al., 2007 offer a DPSIR framework analysis of policy changes (responses) over a 20 year period implemented to address heavy metal contamination of the Seine River basin in France. In their study, Maybeck's team uses historical water quality and industrial output and economic data from the 1930s through 2000 to recreate the Driver - Pressure - State - Impact framework operating within the river basin during that period. They also outline policy initiates (Responses) taken to address the Impacts of the contamination and to assess the effectiveness of those Responses.

This retrospective reconstruction offers a possible technique to compress the Response initiation timeline; particularly at the local or regional level and especially when combined with aggressive stakeholder involvement early on in the DPSIR framing process. Similar ecosystem studies in the near shore environments of the Adriatic Sea (Colelli, et al., 2012), Beaufort Sea (Naidu et al., 2012), and the silver mining district of Bolivia (Hagan et al., 2011) can be re-framed to incorporate DPSIR factors. Such an approach would provide guidance on environmental feedback (Impact or State) timing and the effectiveness of past and future policy Response alternatives.

\section{Systematizing Environmental Indicators}

OECD recognize over 100 environmental indicators (OECD, 2012). The organization and systematic aggregation of these indicators into indices - quantitative devices capable of summarizing and presenting key environmental status or trend information to policy-makers - is of critical importance in assessing their usefulness and reliability. There also are dozens of environmental and sustainability indices, the majority of which feature the same or similar environmental indicators, but aggregate them in different ways. The degree and complexity of indicator aggregation adds another aspect to the evaluative process of environmental index usefulness. This is especially true for those non-scientists who are looking for a tool or set of tools that are easily understood and upon which economic or administrative decisions can be based.

Research has highlighted examples of "index fatigue" where decision makers are overwhelmed by the multifaceted nature of environmental indices or indicators and the information these metrics are trying to present (Smeets and Weterings, 1999; Bell, 2012). The perceived lack of transparency or simplicity in some environmental indices can lead to suspicion on the part of stakeholders, who come to believe that the index harbors the researcher's policy or political point of view (Wilson et al, 2007).

Several meta studies have presented frameworks to organize or categorize individual or types 
of sustainability or environmental indices (Spangenberg et al., 2002; Singh et al., 2009; Wilson et al., 2007). While useful, these rely on concepts or schemas proposed by individual academics or scholars; they lack universality and, more importantly, do not readily accommodate the underlying basis of most indexing systems - individual environmental indicators.

Using the DPSIR framework, the myriad environmental indicators and their associated indexes can be arranged into categories that are distinct, well defined and transferrable; regardless of the degree or intensity of aggregation. Kohsaka (2010) conducted a similar, although broader scale, analysis of the published environmental indicator literature using an analogous methodology. The DPSIR index assignment approach described here allows for indicator bias, intentional or not, to be seen and understood by policy makers and stakeholders. In addition, it permits the development of an index silhouette or contour that illustrates how the index is organized and what values it relies upon.

This process involves disregarding by what means the indicators are weighted or aggregated and deconstructing the index into its component environmental or sustainability indicators. Each indicator is assigned to a DPSIR category and then plotted to illustrate which DPSIR factor is most common in its development. Using this approach, indicator sets and indices can be classified as either Pressure driven, State driven, or Response driven. The following three examples illustrate this technique.

\subsection{Example No. 1 - State of the Great Lakes}

In 1972 Canada and United States agreed to develop a program to evaluate and monitor ecological and environmental quality within the Great Lakes and their associated drainage basins (EC and USEPA, 2009). The Great Lakes Water Quality Agreement eventually led to the selection of 80 environmental and socioeconomic indicators that are assessed regularly and provide researchers and policy makers with information on individual lake or ecosystem-wide performance and status. In 2009 Environment Canada and U.S. Environmental Protection Agency reported on 62 indicators organized into eight categories focused on management issues (e.g., invasive species) or geographic areas (e.g., coastal zones). This joint report concluded that the environmental quality of the Great Lakes ecosystem was mixed, with some areas improving and others becoming worse.

Figure 2 provides a re-arranged architecture for the indicators used in the compilation of the 2009 State of the Great Lakes report. 


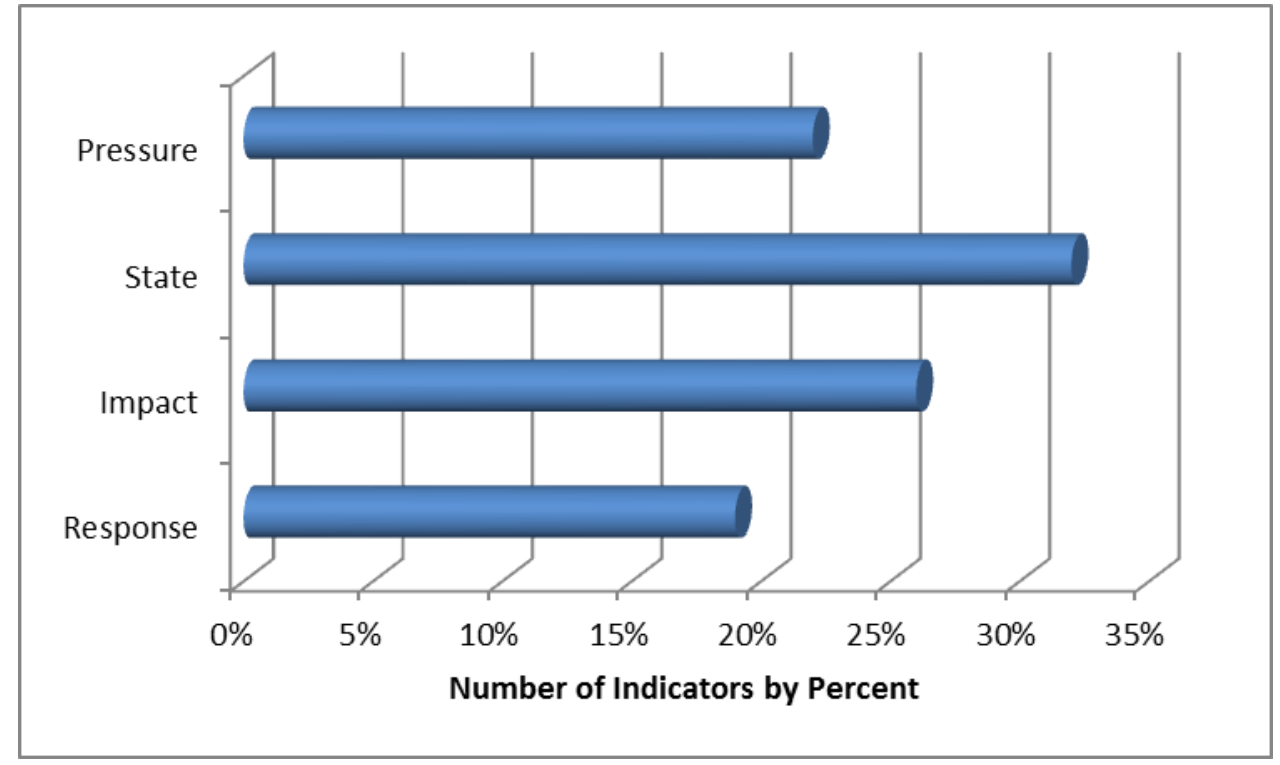

Figure 2. Great Lakes Indicators Distribution. Indicators have been re-arranged to illustrate the architecture underlying the selection and use of ecosystem metrics

A different paradigm emerges if the 62 indicators are re-categorized using the DPSIR framework, rather than those relating to geography or policy concerns. This approach reveals a set of well-balanced indicators which, if aggregated, have the potential to provide an integrated assessment of Great Lakes eco-system status and trends. The State of the Great Lakes report is one where State and Impact dominate the indicator sets being used in data compilation and analysis.

\subsection{Example 2 - Environmental Performance Index}

Developed jointly by Yale and Columbia Universities, the Environmental Performance Index (EPI) aggregates 22 indicators from 10 policy categories to quantitatively benchmark performance and track movement towards environmental policy goals (Emerson et al., 2012). The selected indicators are largely outcome-oriented, attempting to measure results (changes in infant mortality) as opposed to process (number of air quality measurements made). The developers of EPI intend it to be used by policy makers, environmental scientists, advocates, and the general public in evaluating the effectiveness of pollution management programs and trends in environmental quality. 


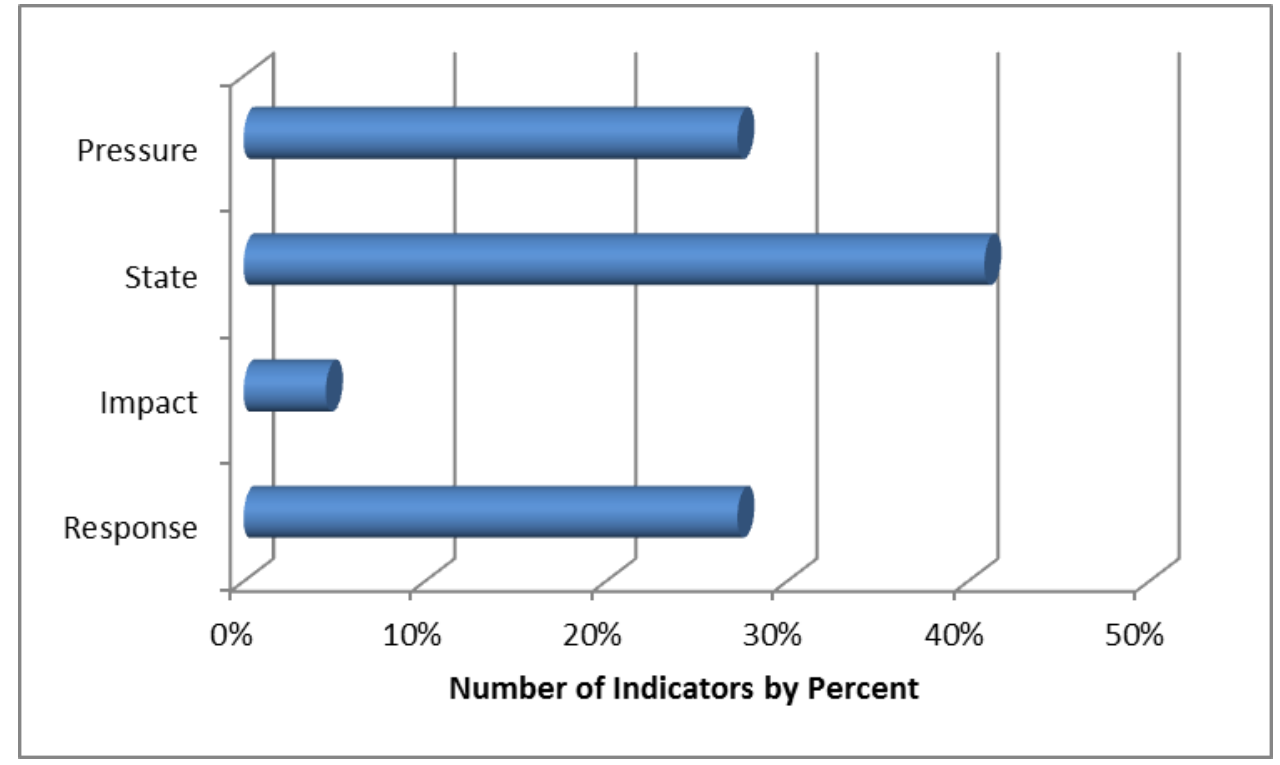

Figure 3. EPI Indicator Distribution. Re-aggregation of EPI indicators into the PSIR framework illustrates the emphasis placed on State versus Impact

Given the stated objectives of the EPI, the environmental indicators aggregated by the index are biased towards those reflecting State, the condition or status of the environment at a given time and place (Figure 3). The number of State indicators is almost double those used to evaluate Pressure or Response, with measures of Impacts comprising only about five percent.

\subsection{Example 3 - State of the Nation's Ecosystem 2008}

Prepared by The Honorable John Heinz III Center for Science, Economics and the Environment - The Heinz Center, a non-governmental organization - the State of the Nation's Ecosystem is a periodic report that compiles 108 indicators to describe the status and condition of six principal ecosystem components: coasts and oceans, farmlands, forests, fresh waters, grasslands and shrub lands, and urban and suburban areas (The Heinz Center, 2008). These indicators (Figure 4) are used to identify patterns in ecosystem extent, their chemical and physical characteristics, biological performance information, and the level of natural ecosystem services (human exploitation). The report does not attempt to aggregate the data into an index or to use the indicators as part of a larger policy objective. 


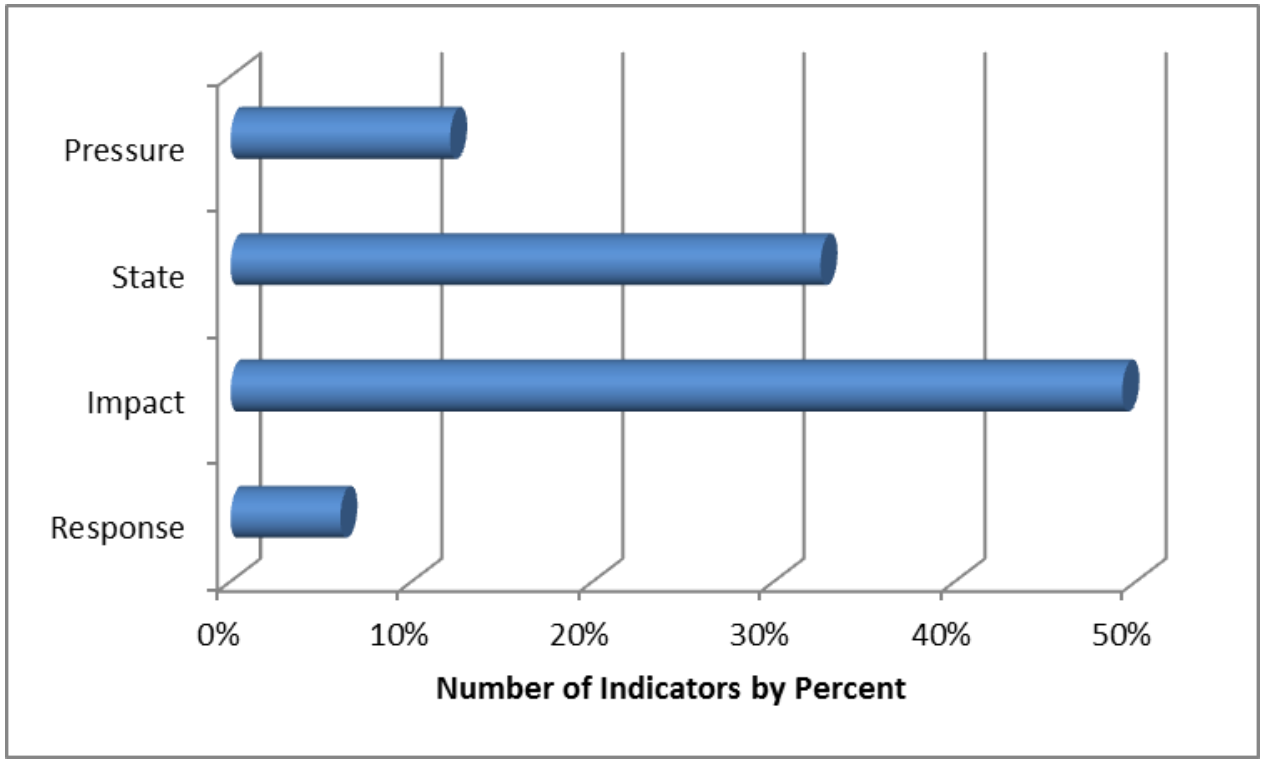

Figure 4. Heinz Report Indicator Distribution by PSIR Categories. Sorting indicators into a PSIR framework allows for a ready comparison with other environmental performance studies

Over 80 percent of the Heinz Report indicators are those related to Impact and State, which is consistent with the report's stated mission. However, Pressure indicators are under-represented, making up just over 10 percent of the data set and it would be these indicators that best describe the extent of human demands on ecosystem services.

\section{Conclusion}

The selection of environmental indicators in these three examples define data sets that are focused on different parts of the DPSIR framework. Indicators making up the Great Lakes data set are well balanced, while those in the EPI emphasize State indicators and minimize those describing Impacts. Such a bias may be mitigated through the EPI aggregating process that weighs the indicators using a complex series of algorithms. Heinz Report indicators consider Impacts and States more frequently than Pressures or Responses.

Omission or under-representation of environmental Pressures, Impacts, or Responses may limit the usability of the data sets, providing only a two-dimensional (State and Impact) view of environmental quality trends or patterns. Rapport and Hilden (2013) analysis of ecological indicators in use at the Baltic Sea illustrate the consequences of a non-holistic approach. Of 37 indicators mandated by the Helsinki Commission (HELCOM: an intergovernmental organization of nine Baltic Sea coastal countries and the European Union) all are either related to Pressure or State, as shown in Table 2: 
Table 2. Summary of the types of ecological indicators used in evaluation of Baltic Sea environmental quality (from Backer, 2008)

\begin{tabular}{|l|l|c|}
\hline TYPE & DESCRIPTION & NUMBER \\
\hline Pressure & Nitrogen and phosphorus & 3 \\
\cline { 2 - 3 } & Heavy Metals & 3 \\
\cline { 2 - 3 } & Dioxin & 2 \\
\cline { 2 - 3 } & Illegal discharges & 1 \\
\hline \multirow{5}{*}{ States } & Water chemistry and appearance & 7 \\
\cline { 2 - 3 } & Nutrient concentrations & 2 \\
\cline { 2 - 3 } & Heavy metals & 5 \\
\cline { 2 - 3 } & Organic and radiological pollutants & 6 \\
\cline { 2 - 3 } & $\begin{array}{l}\text { Bacterioplankton and } \\
\text { phytoplankton }\end{array}$ & 7 \\
\cline { 2 - 3 } & Coastal fish & 1 \\
\hline
\end{tabular}

While they acknowledge the complexity of HELCOM's mission, Rapport and Hilden point out that little attention has been given to the role of Drivers and Responses in Baltic Sea ecosystem study. As a consequence, there is a significant lack of specific guidance on how to move from the problem to a solution. Despite water quality, habitat, and species studies that have been ongoing since the 1970s, Baltic Sea environmental quality remains highly challenged (HELCOM, 2013).

Along similar lines, Courville (2003) describes how the Costa Rican government's almost singular focus on maximizing economic return for its coffee growing industry (yield as measured in dollars per hectare) has led to widespread, almost catastrophic environmental degradation. In many regions, high intensity, fertilizer and pesticide dependent cultivation methods have exhausted the soil and increased rates of erosion. As a result, Cost Rica is in the midst of a major educational campaign to retrain its growers in the use of more sustainable techniques. She compares this to Mexican grower's more encompassing social indicator based framework. In addition to a "fair return for producers", these include such benchmarks as lower child and women labor rates, better access to housing and medical care, and more educational opportunities.

Martins et al., (2012) recognize the need for a comprehensive set of balanced DPSIR based gauges to support fisheries management strategies. Based on a review of the literature, they highlight inaccuracies and inconsistencies in the application or utilization of indicators within this important economic and ecosystem resource. Martins et al., advocate a schema that identifies a framework of measures encompassing 14 Drivers, 13 Pressures, 13 Impacts/States and 16 Response indicators. Adoption of their balanced approach would serve to establish a common set of indicators useful in assessing fishery sustainability and help to make more consistent the ability to measure the success of policy initiatives.

As illustrated by the above examples, for environmental indicator sets or indices to be 
credible, representative of ecosystem performance, and provide meaningful feedback on policy they need to be holistic and inclusive. The fragmentation and re-assembly of environmental indictor data sets or indices proposed here is an attempt to underscore those areas where environmental indicator schemas may be weak or not sufficiently inclusive to achieve their stated assessment objectives.

\section{Acknowledgement}

The author is grateful to Dr. Michael Greenberg of Rutgers University for his critical review of the paper.

\section{References}

Aguilera-Caracuel, J., Aragon-Correa, J. A., Hurtado-Torres, N. E., \& Rugman, A. M. (2012). The effects of institutional distance and headquarter's financial performance on the generation of environmental standards in multinational companies. Journal of Business Ethics, 105, 461-474. http://dx.doi.org/10.1007/s10551-011-0978-7.

Babcicky, P. (2012). Rethinking the foundations of sustainability measurements: The limitations of the environmental sustainability index (ESI). Social Indicators Research, 107. http://dx.doi.org/10.1007/s11205-012-0086-9.

Backer, Hermanni (2008). Indicators and scientific knowledge in regional Baltic Sea environmental policy. ICES Journal of Marine Science, 65(8), 1398-1401. http://dx.doi.org/10.1093/icesjms/fsm157.

Bauler, T. (2012). An analytical framework to discuss the usability of (environmental) indicators for policy. Ecological Indicators, 17(38-45). http://dx.doi.org/10.1016j.ecolind.2011.05.013.

Bell, S. (2012). DPSIR = A problem structuring method? An exploration from the "imagine" approach. European Journal of Operational Research, 222, 350-360. http://dx.doi.org/10.1016/jejor.2012.04.029.

Bertollo, P. (March 1998). Assessing ecosystem health in governed landscapes: A framework for developing core indicators. Ecosystem Health, 4(1), 33-51.

Binimelis, R., Monterroso, I., \& Rodriguez-Labajos, B. (2009). Catalan agriculture and genetically modified organisms (GMSs) - an application of DPSIR model. Ecological Economics, 69, 55-62. http://dx.doi.org/10.1016/jecolecon.2009.02.003.

Boychuk, R. (2011). The boreal handshake. Canadian Geographic, 131(1), 30.

Burtraw, D., Evans, D. A., \& Krupnick, A. (2005). Economics of pollution trading for $\mathrm{SO}_{2}$ and NOx. Annual Review of Environment and Resources, 30, 253-289. http://dx.doi.org/10.1146/annurevenergy.30.081804.121028.

Carr, E. R., Wingard, P. M., Yorty, S. C., Tompson, M. C., Jensen, N. K., \& Roberson, J. (2007). Applying DPSIR to sustainable development. International Journal of Sustainable Development \& World Ecology, 14, 543-555. http://dx.doi.org/10.1080/13504500709469753. 
Cendrero, A., Francés, E., \& Del Corral, D. (2003). Indicators and indices of environmental quality for sustainability assessment in coastal areas; application to case studies in Europe and the Americas. Journal of Coastal Research, 19(4), 919.

Collins, A., Munday, M., \& Roberts, A. (2012). Environmental consequences of tourism consumption at major events: An analysis of the UK stages of the 2007 tour de France. Journal of Travel Research, 51(5), 577-590. http://dx.doi.org/10.1177/0047287511434113.

Conacher, A. (1998). Environmental quality indicators: Where to from here? Australian Geographer, 29(2), 175-189.

Covelli, S., Langone, L., \& Acquavita, A. (2012). Historical flux of mercury associated with mining and industry sources in the Marano and Grado lagoon (northern Adriatic Sea). Estuarine Coastal and Shelf Science, 113, 7-19. http://dx.doi.org/10.1016/j.ecss.2011.12.038.

Emerson, J. W., Hsu, A., Levy, M. A., de Sherbinin, A., Mara, V., Esty, D. C., et al. (2012). Environmental performance index and pilot trend environmental performance index. New Haven, Connecticut: Yale Center for Environmental Law and Policy.

Environment Canada and U.S. Environmental Protection Agency. (2010). State of the Great Lakes 2009 No. EPA 905-R-09-031) Environment Canada and U.S. Environmental Protection Agency.

Esty, Dan and Samuel-Johnson, Kim. (2001). Environmentalism by number. World Link, 14(1), 23-26.

European Commission, 2012. Joint Research Center, European Soil Portal - Soil Data and Information System. http://eusoils.jrc.ec.europa.eu/InternationalCooperation/SEPLS.

Feeley, R. A., Sabine, C. L., Kitack, L., Berelson, W., Kleypas, J., Fabry, V. J., et al. (2004). Impact of anthropogenic $\mathrm{CO}_{2}$ on the $\mathrm{CaCO}_{3}$ system in the oceans. Science, 305(5682), 362-366.

Gabrielsen, P., \& Bosch, P. (2003). Environmental indicators: Typology and use in reporting EEA internal working paper) European Environment Agency. http://www.stakeholderforum.org/fileadmin/files

Giannetti, B. F., Bonilla, S. H., Silva, C. C., \& Almeida, C. M. V. B. (2009). The reliability of experts' opinions in constructing a composite environmental index: The case of ESI 2005. Journal of Environmental Management, $\quad 90, \quad 2448-2459$. http://dx.doi.org/10.1016/jenpol.2008.12.018.

Greenpeace International (2010). Canadian boreal forest agreement. Greenpeace Update, 10.

Hagan, N., Robins, N., Hsu-Kim, H., Halabi, S., Morris, M., Woodall, G., et al. (2011). Estimating historical atmospheric mercury concentrations from silver mining and their legacies in present-day surface soil in Potosi, Bolivia. Atmospheric Environment, 45(40), 7619. http://dx.doi.org/10.1016/j.atmosenv.2010.10.1009.

HELCOM, 2013. Activities Report 2012, Baltic Sea Environment Proceedings No. 134. 
http://www.helcom.fi/stc/files/Publications/Proceedings/bsep134.pdf.

Hoag, D. L., Ascough II, J. C., \& Engler-Palmer, A. (2002). The impact matrix approach and decision rules to enhance index dimensionality, flexibility and representation. Ecological Indicators, 2, 161-168.

Hong, K. S., \& Lee, A. J. (2006). Global environmental changes in terrestrial ecosystems. international issues and strategies solutions: Introduction. Ecological Research, 21, 783-787. http://dx.doi.org/10.1007/s11284-006-0032-x.

Hughes, G. (2002). Environmental indicators. Annals of Tourism Research, 29(2), 457-477.

Karageorgis, A. P., Kapsimalis, V., Kontogianni, A., Skourtos, M., Turner, K. R., \& Salomons, W. (2006). Impact of 100-year human interventions on the deltaic coastal zone of the inner Thermaikos gulf (Greece): A DPSIR framework analysis. Environmental Management, 38(2), 304-315. http://dx.doi.org/10.1007/s00267-004-0290-8.

Kennish, M. J., Bricker, S. B., \& Dennison, W. C. (2007). Barnegat Bay-Little Egg Harbor Estuary: Case study of a highly eutrophic coastal bay system. Ecological Applications, 17(5), S3-S16.

Knudsen, S., Zengin, M., \& Mahmut, H. K. (2010). Identifying drivers for fishing pressure. A multidisciplinary study or trawl and sea snail fisheries in Samsun, Black Sea coast of Turkey. Ocean \& Coastal Management, 252-269. http://dx.doi.org/10.1016/j.ocecoaman.2010.04.008.

Kohsaka, R. (2010). Developing biodiversity indicators for cities: Applying the DPSIR model to Nagoya and integrating social and ecological aspects. Ecological Research, 25(925-936). http://dx.doi.org/10.1007/s11284-010-0746-7.

Kolk, A., \& and Mauser, A. (2002). The evolution of environmental management: From stage models to performance evaluation. Business Strategy and the Environment, 11, 14-31. http://dx.doi.org/10.1002/bse.316.

Kristensen, P. (2004). The DPSIR framework. National Environment Research Institute, Department of Policy Analysis, European Centre on Water, European Environment Agency, Denmark.

Lee, K. N. (2001). Human-environment relationship: Indicators. In N. J. Smeiser, J. Wright, \& P. B. Baltes (Eds.), International encyclopedia of the social \& behavioral sciences (1st ed., pp. 7045-7050). Maryland Heights, Missouri: Elsevier Limited.

Lin, T., Lin, J., Cui, S., \& Cameron, S. (2009). Using a network framework to quantitatively select ecological indicators. Ecological Indicators, 9, 1114-1120. http://dx.doi.org/10.1016/j.ecolind.2008.12.009.

Malville, J. M. (2012). A guide to prehistoric astronomy in the southwest. Boulder, Colorado: 3D Press.

Martins, Joana H., Camanho, Ana S., \& Miguel B. Gaspar (2012). A review of the application 
of driving forces - Pressure - State - Impact - Response framework to fisheries management. $\begin{array}{llll}\text { Ocean } \quad \text { C } & \text { Coastal } & \text { Management, } & 69,\end{array}$ http://dx.doi.org/10.1016/j.ocecoaman.2012.07.029.

Maxim, L., \& Spangenberg, J. H. (2009). Driving forces of chemical risk for the European $\begin{array}{llll}\text { biodiversity. } & \text { Ecological } & \text { Economics, } & \text { 63-54. }\end{array}$ http://dx.doi.org/10.1016/j.ecolecon.2009.03.010.

Mayer, A. L. (2008). Strengths and weaknesses of common sustainability indices for multidimensional systems. Environment International, 34, 277-291. http://dx.doi.org/10.1016/j.envint.2007.09.004

Meybeck, M., Lestel, L., Bonte, P., Moilleron, R., Colin, J. L., Rousselot, O., et al. (2007). Historical perspective of heavy metals contamination $(\mathrm{Cd}, \mathrm{Cr}, \mathrm{Cu}, \mathrm{Hg}, \mathrm{Pb}, \mathrm{Zn})$ in the Seine River basin (France) following a DPSIR approach (1950-2005). Science of the Total Environment, 375, 204-231. http://dx.doi.org/10.1016/j.scitotenv.2006.12.017

Mourao, I., Caeiro, S., Costa, M. H., Ramos, T. B., \& Painho, M. (2004). Application of the DPSIR model to the Sado estuary in a GIS context - social and economic pressures. Proceedings of 7th Conference on Geographic Information Science, Crete, Greece. pp. 391-402.

Naidu, A. S., Blanchard, A. L., \& Misra, D. (2012). Historical changes in trace metals and hydrocarbons in near shore sediments, Alaskan Beaufort Sea, prior and subsequent to petroleum related industrial development: Part I. Trace Metals. Marine Pollution Bulletin, 64(10), 2177-2189. http://dx.doi.org/10.1016/j.marpolbul.2012.07.037

Newhoff, K., Martinez, K. J., \& Sato, M. (2006). Allocation, incentives and distortions: The impact of EU ETS emissions allowance allocations to the electricity sector. Climate Policy, 6(1), 73-91.

Niemeijer, D. (2002). Developing indicators for environmental policy: Data-driven and theory-driven approaches examined by example. Environmental Science \& Policy, 5, 91-103. http://dx.doi.org/10.1016/s1462-9011(02)00026-6.

Niemeijer, D., \& DeGroot, R., S. (2008). Framing environmental indicators: Moving from causal chains to causal networks. Environmental Development and Sustainability, 10, 89-106. http://dx.doi.org/10.1007/s10668-006-9040-9.

OECD. (2008). Handbook on constructing composite indicators: Methodology and user guide. Organisation for Economic Co-Operation and Development, OECD Publishing.

Organization for Economic Co-operation and Development. (2010). OECD factbook 2010: Economics, environmental and social statistics OECD Publishing. http://dx.doi.org/10.178/factbook-2010-en.

Old farmer's almanac (2010). OFA.

Potschin, M. (2009). Land use and the state of the natural environment. Land use Policy, 26S, 
S170-S177. http://dx.doi.org/10.1016/j.landusepol.2009.08.008

Radu, M. (2012). Empirical study on the indicators of sustainable performance - the sustainability balanced scorecard, effect of strategic organizational change. Sustainable and Organization Change, 14(32), 451-469.

Robbins, P. (2001). Tracking invasive land covers in India, or why our landscapes have never been modern. Annals of the Association of American Geographers, 91(4), 637-659.

Roeder Martin, S. (2008). Continued protection of the bald eagle after delisting. The Florida Bar Journal, (July/August), 44-48.

Schakenbach, J., Vollaro, R., \& Forte, R. (2006). Fundamentals of successful monitoring, reporting, and verification under a cap and trade program. Journal of the Air \& Waste Management Association, 56(11), 1576.

Sekovski, I., Newton, A., \& Dennison, W. (2012). Megacities in the coastal zone: Using a driver-pressure-state-impact-response framework to address complex environmental problems. Estuarine Coastal and Shelf Science, 96, 48-59. http://dx.doi.org/10.1016/j.ecss2011.07.011.

Singh, R. K., Murty, H. R., Gupta, S. K., \& Dikshit, A. K. (2012). An overview of sustainability assessment methodologies. Ecological Indicators, 15, 281-299. http://dx.doi.org/10.1016/j.ecolind.2011.01.007.

Siracusa, G., LaRosa, A. D., \& Sterlini, S. E. (2004). A new methodology to calculate the environmental protection index $\left(\mathrm{E}_{\mathrm{p}}\right)$, A case study applied to a company producing composite materials. Journal of Environmental Management, 73, 276-284. http://dx.doi.org/10.1016/j.envman.2004.04.006.

Smeets, E., \& Weterings, R. (1999). Environmental indicators: Typology and overview. Technical Report No. 25). Copenhagen, Denmark: European Environment Agency.

Spahr, R. (2011, January 5, 2011). Christie signs Barnegat Bay legislation in Ocean County. Press of Atlantic City.

Spangenberg, J., Martinez-Alier, J., Omann, I., Monteroso I., \& Binimelis R. (2009). The DPSIR scheme for analyzing biodiversity loss and developing preservation strategies. Ecological Economics, 69, 9-11. http://dx.doi.org/10.1016/j.ecolecon.2009.04.024.

Spangenberg, J., Pfahl, S., \& Deller, K. (2002). Towards indicators for institutional sustainability: Lessons from an analysis of Agenda 21. Ecological Indicators, 2, 61-77. http://dx.doi.org/10.1016/s1470-160x(02)00050-x.

The Heinz Center. (2008). The state of the nation's ecosystems 2008. Washington D.C.: The H. John Heinz III Center for Science, Economics and the Environment.

Thomas, S., Repetto, R., \& Dias, D. (2007). Integrated environmental and financial performance metrics for investment analysis and portfolio management. Corporate Governance, 15(3), 421-426. http://dx.doi.org/10.1111/j.1467-8683-2007.00575.x 


\section{Macrothink}

Tscherning, K., Helming, K., \& Krippner, B. (2012). Does research applying the DPSIR framework support decision making? Land use Policy, 29(1), 102-110. http://dx.doi.org/10.1016/j.landusepol.2011.05.009.

U.S. Environmental Protection Agency (EPA). (2009). Air quality index: A guide to air quality and your health No. EPA-456/F-09-002). Research Triangle Park, North Carolina: Office of Air Quality Planning and Standards.

United Nations Environmental Programme (UNEP. (2006). Environmental indicators for North America. Nairobi, Kenya: United Nations Environmental Programme.

van den Butter, F. A. G., \& van der Eyden, J. A. C. (1998). A pilot index for environmental policy in the Netherlands. Energy Policy, 26(2), 95-101.

Wilson, J., Tyedmers, P., \& Peiot, R. (2001). Contrasting and comparing sustainable development indicator metrics. Ecological Indicators, 7(2), 299-314. http://dx.doi.org/10.1016/j.ecolond.2006.02.009.

\section{Copyright Disclaimer}

Copyright reserved by the author.

This article is an open-access article distributed under the terms and conditions of the Creative Commons Attribution license (http://creativecommons.org/licenses/by/3.0/). 